\title{
The optimal time for sampling macroinvertebrates and its implications for diversity indexing in rheocrenes - case study from the Prokletije Mountains
}

\author{
Violeta Berlajolli ${ }^{1}$, Mateusz Płóciennik ${ }^{2, *}$, Olga Antczak-Orlewska ${ }^{2}$, and Vladimir Pešic ${ }^{3}$ \\ ${ }^{1}$ University of "Haxhi Zeka", 30000 Peje/Pec, Republic of Kosovo \\ 2 Department of Invertebrate Zoology and Hydrobiology, University of Lodz, 12/16 Banacha St 90-237, Lodz, Poland \\ ${ }^{3}$ Department of Biology, University of Montenegro, Cetinjski put b.b., 81000 Podgorica, Montenegro
}

\begin{abstract}
In most studies, sampling of springs has typically been undertaken over one season, which has raised the question what the most suitable time(s) to undertake sampling is. In this study, we report the results of macroinvertebrate monthly samplings performed in two springs in western Kosovo in order to determine the most appropriate time to undertake sampling to characterise biodiversity. Diversity indices have revealed that insect assemblages remain more diverse than assemblages of fully aquatic invertebrates. The results of SIMPER have revealed that winter communities remain the most dissimilar one another and also to other seasons. However, when Gammarus balcanicus is excluded, this pattern becomes blurred. To sum up, our results illustrate that (1) multiple surveys covering more than one season provide a comprehensive picture of total biodiversity, and (2) for appropriate characterising of the macroinvertebrate community in the studied rheocrenes at least winter and summer were required.
\end{abstract}

Keywords: Spring habitat / quantitative sampling / species richness / seasonal variability / Gammarus balcanicus

Résumé - Le moment optimal pour l'échantillonnage de macro-invertébrés et ses implications pour l'indexation de la diversité chez les rhéocrènes - étude de cas dans les monts Prokletije. Dans la plupart des études, l'échantillonnage des sources est généralement réalisé sur une saison, ce qui a soulevé la question de savoir quel(s) moment(s) le plus approprié(s) pour entreprendre l'échantillonnage. Dans cette étude, nous présentons les résultats d'échantillonnages mensuels de macroinvertébrés effectués dans deux sources du nord du Kosovo afin de déterminer le moment le plus approprié pour entreprendre l'échantillonnage pour caractériser la biodiversité. Les indices de diversité ont révélé que les assemblages d'insectes demeurent plus diversifiés que les assemblages d'invertébrés entièrement aquatiques. Les résultats de SIMPER ont révélé que les communautés hivernales demeurent les plus différentes les unes des autres et aussi des autres saisons. Cependant, lorsque Gammarus balcanicus est exclu, ce schéma devient flou. En résumé, nos résultats illustrent que 1 - des études multiples couvrant plus d'une saison fournissent une image complète de la biodiversité totale, et 2 - pour une caractérisation appropriée de la communauté de macroinvertébrés dans les rhéocènes étudiés, au moins hiver et été étaient nécessaires.

Mots-clés: Habitat rhéocrène / échantillonnage quantitatif / richesse spécifique / variabilité saisonnière / Gammarus balcanicus

\section{Introduction}

In most recent studies, springs have been widely recognised as important freshwater sites maintaining high biodiversity, especially in mountainous regions (Pešić et al., 2016; von Fumetti et al., 2017; Savić et al., 2017). They are inhabited by a

\footnotetext{
*Corresponding author: mplociennik10@outlook.com
}

number of rare, even endemic species, many of which are spring specialists, the so-called crenobionts (von Fumetti et al., 2017). These ecosystems are often considered as very sensitive to various anthropogenic impacts, such as drainage of springs and other types of human activities that reduce spring biodiversity (Savić et al., 2017; Pešić et al., in press). Moreover, spring ecosystems today face ongoing climatic changes that include hydrologic disturbances in the form of flood and drought (Dmitrović et al., 2016; von Fumetti et al., 2017). 
Despite the general recognition of biodiversity of springs and the ecosystem service provision they supply, springs are not included in some of widely adopted conservation strategies (Pešić et al., in press). For example, despite the fact that the EU Water Framework Directive requires at least 'good' ecological status or 'good ecological potential' in all surface waters, due to their small dimensions, springs are not included in common assessment tools (EC, 2003). Routine monitoring activities of these ecosystems are rarely undertaken, which indicates that progress towards good ecological status in spring habitats and the incorporation of springs into national bio-monitoring programmes is limited. This may be due to the fact that there is no standardised protocol that determines the methods and frequency of sampling. In most studies, spring communities have been collected once (e.g. Gerecke et al., 2007; Kubíková et al., 2012; Dmitrović et al., 2016; Płóciennik et al., 2016), rarely more frequently over two or three sampling seasons (e.g. von Fumetti et al., 2006) or even throughout all the seasons (Bottazzi et al., 2011; Pešić et al., 2016), but monthly quantitative sampling are generally lacking.

In most studies, spring biodiversity samples have been collected in summer (e.g. Gerecke et al., 2011). One of the reasons for this certainly lies in the fact that the existing assessment procedures for spring habitats suggest sampling of multiple groups of organisms such as meiofauna, diatoms and peryphyton (Gerecke et al., 2011). For meiofauna, the optimal time for sampling would be early summer, for peryphyton, it would be autumn, while the end of summer is considered as the optimal period for documenting diversity of diatom algae (Gerecke et al., 2011).

Macrobenthic spring fauna is diverse, including fully aquatic taxa and aquatic insects with the terrestrial dispersal stage (Botosaneanu, 1998). These two ecological groups have different life cycles, which complicates the sampling strategy. Aquatic insects with the terrestrial dispersal stage emigrate and thus disappear for part of the year from benthic samples. It implies that diversity of fully aquatic taxa and insects may differ substantially and thus affect total measured diversity. One of the broadly distributed crustacean taxa in Balkan springs and streams is Gammarus balcanicus agg. (e.g. Mamos et al., 2014). It may reach high abundance in rheocrene communities. This raises the question of how important the life cycle of this single species is for phenology of the whole spring assemblage.

A spring survey strongly depends on phenology, and thus seasonal temperature fluctuations. Temperature remains one of the most important factors in springs classification dividing springs into cold, thermal and hot ones. Temperate zone springs are commonly regarded as being constantly cool, which should be of special importance for cold-stenotherm organisms. However, small rheocrenes may reveal both diurnal and annual variability with the temperature ranging from nearly 0 to $15^{\circ} \mathrm{C}$. It depends on the water supply, altitude and rate of discharge.

The aims of our study were to (1) identify the main pattern of Prokletije Mts. spring assemblage composition phenology, and (2) identify the season which would be optimal for a faunistic survey conducted in order to characterise the maximum diversity that spring communities can reach in Western Balkan mountainous regions. We hypothesise that (1) G. balcanicus as the dominant species in Prokletije Mountain springs determines the spring benthos diversity values and

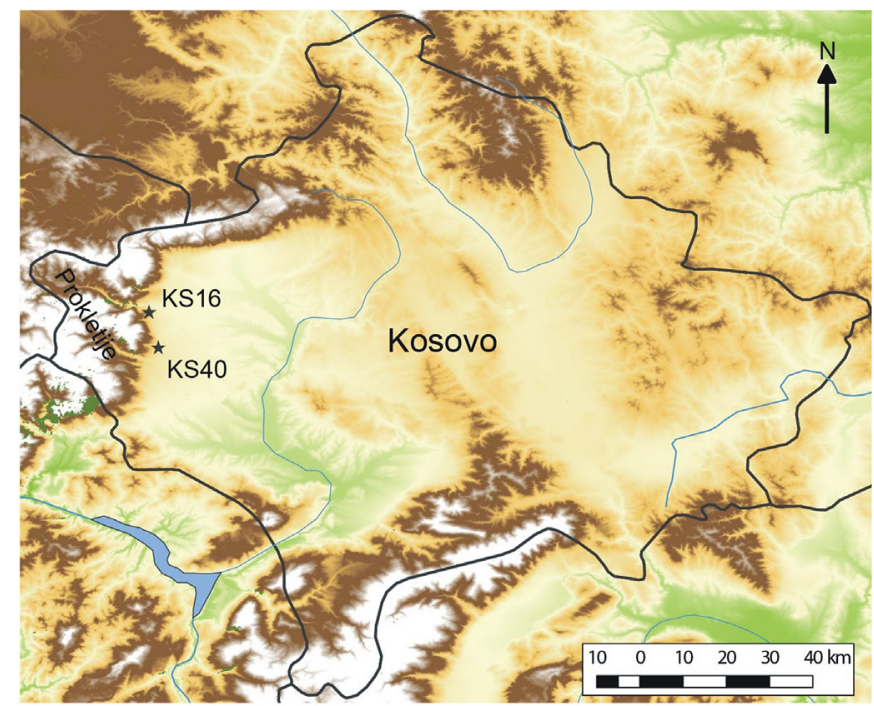

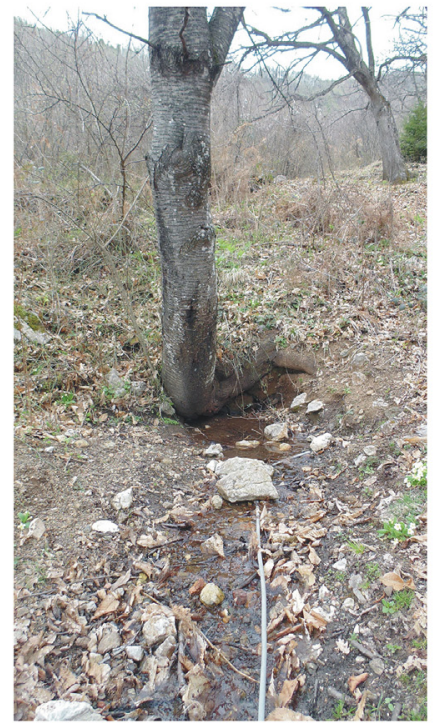

KS 16

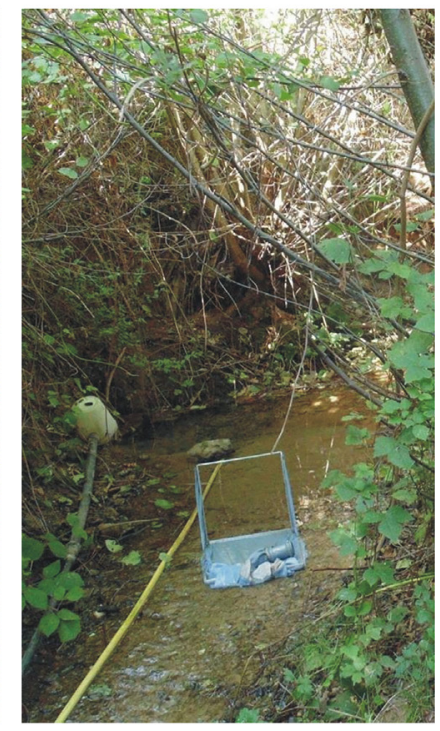

KS 40
Fig. 1. The map of the Kosovo Republic with marked study sites and photos of sampled springs KS16 and KS40 (generated in QGIS (http://qgis.org), layer files acquired from the USGS (https://www. usgs.gov/) and Natural Earth (http://www.naturalearthdata.com/)).

composition pattern, (2) the aquatic insects' life cycle substantially affects the studied spring communities' phenology, (3) the air temperature does not affect significantly seasonal changes in the studied assemblage composition, (4) if springs in Western Balkans cannot be surveyed each season, then summer is the most suitable time to measure and compare benthos communities' maximum diversity.

\section{Material, methods and study site description}

We studied two springs at the edge of the Prokletije Mountains (the Albanian Alps), near the city of Peja/Peć in western Kosovo (Fig. 1). Spring KS16 (spring Nenqershi, 
$42^{\circ} 38^{\prime} 36^{\prime \prime} \mathrm{N} ; 20^{\circ} 16^{\prime} 36^{\prime \prime} \mathrm{E}, 803 \mathrm{~m}$ a.s.l.) is situated near the city of Peja/Peć in deciduous forests dominated by common beech, and thus shadowed by tree canopies during the growing season. The second spring, KS40 (spring Toplla $42^{\circ} 34^{\prime} 19^{\prime \prime} \mathrm{N}$; $20^{\circ} 17^{\prime} 26^{\prime \prime} \mathrm{E}, 640 \mathrm{~m}$ a.s.1.), is located at the forest edge, near the village of Lebush. Both springs are small $\left(1-2 \mathrm{~m}^{2}\right)$ and have low discharge, $<10 \mathrm{~L} / \mathrm{min}$ (on average: $\mathrm{KS} 167.7 \mathrm{~L} / \mathrm{min}$; KS40 $6.7 \mathrm{~L} / \mathrm{min}$ ). According to the spheres of discharge of springs classification (Springer and Stevens, 2008), KS16 belongs to the hill slope springs ecosystem, with no channel upslope from the source, while KS40 belongs to the rheocrene springs ecosystem, emerging in a drainage, and therefore subject to seasonal flooding. The geological underground consists mainly of limestone. The water of both springs is used for irrigation and watering livestock in summer.

Both springs were characterised by relatively stable physico-chemical parameters. The water temperature remained at a nearly stable level (KS16: $10.9 \pm 1.0^{\circ} \mathrm{C}$; KS40: $\left.13.3 \pm 1.4{ }^{\circ} \mathrm{C}\right)$. The electrical conductivity was higher in $\mathrm{KS} 16(346.5 \pm 9.1 \mathrm{Ms} / \mathrm{cm})$ than in KS40 $(269.75 \pm 5.75 \mathrm{Ms} / \mathrm{cm})$. The $\mathrm{pH}$ was circum-neutral in both springs (KS16: $7.38 \pm 0.63$; KS40: $7.10 \pm 0.42$ ) but varied monthly, reaching the highest values in KS16 during the vegetative season (Appendix 1, Fig. 2). The temperature and $\mathrm{pH}$ were measured with a $\mathrm{pH}$ meter (HI 98103, accuracy 0.2) and the electrical conductivity with a conductometer (HI 98303, accuracy of $\pm 2 \%$ full scale). Additionally, the mean month weather conditions were taken from the Kosovo Environmental Protection Agency (http://www. ammk-rks.net) (Appendix 1).

Macroinvertebrates were collected with a Surber sampler $\left(0.15 \mathrm{~m}^{2}\right.$, mesh size $\left.350 \mu \mathrm{m}\right)$ in the eucrenal of each spring as far as possible without damaging the habitat. All samples were immediately preserved in $96 \%$ ethanol, and subsequently sorted and determined in the laboratory. Macroinvertebrate assemblages were collected monthly from each spring from October 2014 to September 2015 (for the exact sampling dates - see Appendix 1).

All taxa were determined by specialists (Gastropoda P. Glöer, Hirudinea - C. Grosser, Hydrachnidia - V. Pešić, Odonata and aquatic Heteroptera - B. Gligorović, Trichoptera H. Ibrahimi, Ephemeroptera and Plecoptera - T. Kovacs, Chironomidae and other Diptera - M. Płóciennik) to the most accurate taxonomic level (see Appendices 2 and 3). The collection of Chironomidae and Dixidae larvae, mounted on permanent slides, is deposited at the Department of Invertebrate Zoology and Hydrobiology (University of Lodz).

The main community metrics abundance $(\mathrm{N})$, number of taxa $(\mathrm{S})$; rarefaction $(\mathrm{ES}(\mathrm{n}))$ and commonly used diversity indices: Margalef Index(d); Simpson Index (1-Lambda'), Shannon Index (H(loge)) as well Pielou's evenness index (J') were calculated for each of 24 samples. The smallest sample included in the rarefaction analysis comprised nine specimens. The statistical significance indicating differences in biodiversity indices was calculated (1) between combined invertebrate communities (abundances were summed up) of site KS16 and site KS40, and (2) between two ecological groups of invertebrates - 'fully aquatic taxa' and 'aquatic insects with the terrestrial stage', hereinafter referred to as 'insects' (excluding beetles whose adult stages spend most of the time in the water). The Kruskal-Wallis test was performed with STATISTICA software (StatSoft Inc., 2015).
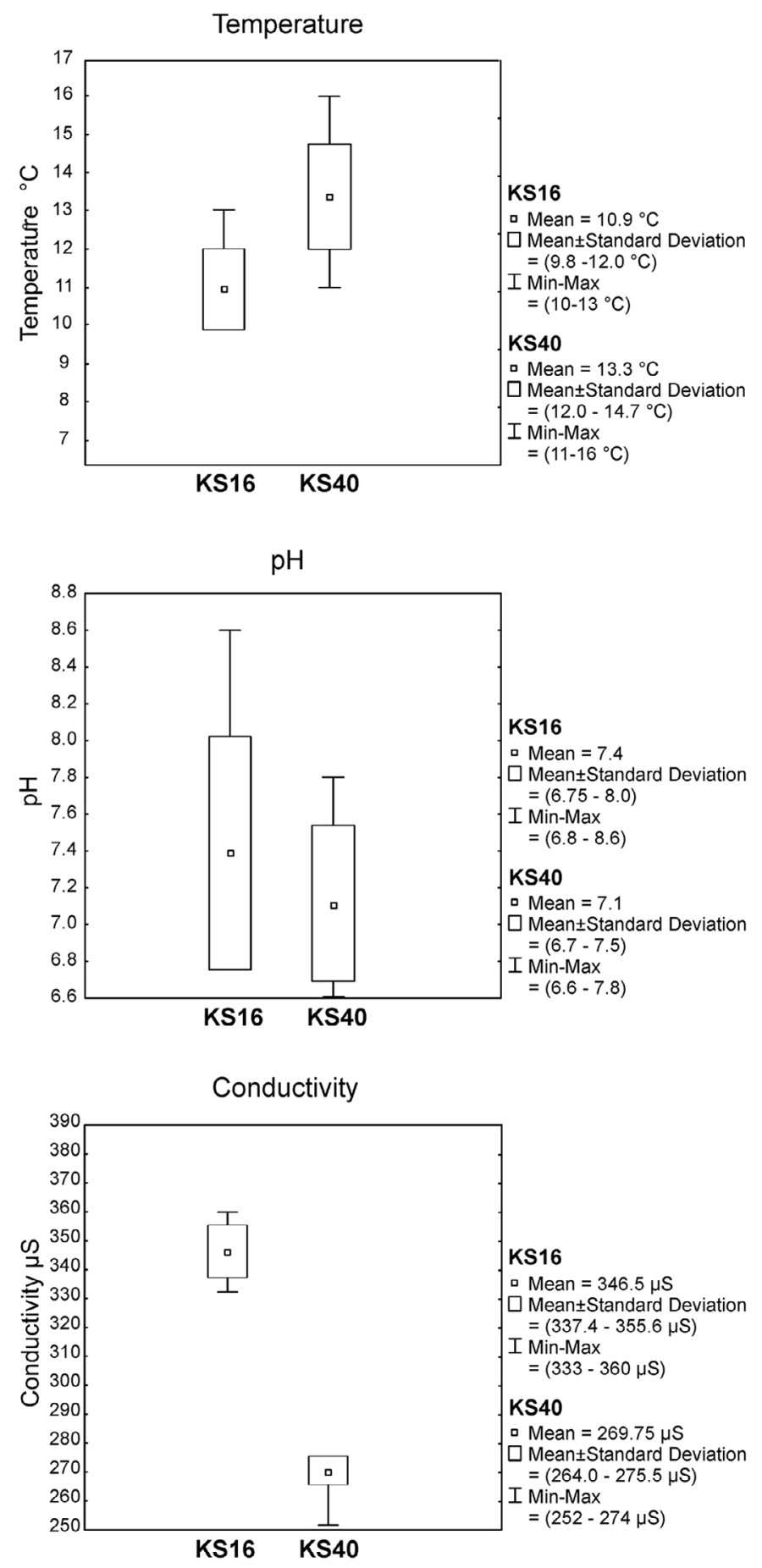

Fig. 2. Water temperature, $\mathrm{pH}$ and conductivity mean, standard deviation and minimum-maximum values at KS16 and KS40 sites.

To find a general pattern in the studied communities, the Bray-Curtis similarity among the samples transformed to percentage was calculated, and (1) non-metric multidimensional scaling (NMDS) with the Kruskal fit scheme 1, minimum stress 0.01 and 50 restarts, as well as (2) group average cluster analysis were performed in two variants: (i) for the whole assemblage, and (ii) for the assemblage when G. balcanicus was excluded. A one-way SIMPER analysis 
based on the percentage transformed data and then Bray-Curtis similarity with cut off for low contributions $=90 \%$ was performed to compare taxonomic discrepancies between sites KS16 and KS40, and the four seasons - winter (December, January, February), spring (March, April, May), summer (June, July, August, September) and autumn (October, November) - at both sites combined together in two variants (for all collected taxa, and with G. balcanicus excluded). A multivariate analysis was conducted with PRIMER 6 (Clarke and Gorley, 2001).

\section{Results}

In total, 51 taxa represented by 2494 specimens were recorded from both studied springs. Among them, three crenobiontic species were found: two water mites Lebertia glabra and Atractides fonticolus (Hydrachnidia), both recorded here as new for Kosovo, and the leech Dina prokletijaca (Hirudinea) endemic to springs of the Prokletije Mountains. The group of fully aquatic invertebrates contains 13 taxa, while approximately two-thirds (38 taxa) belong to insects with the flying dispersive adult stage (Appendices 2 and 3 ).

The mean abundances of all invertebrates taken together in both springs were the highest in summer (992.5 and 1592.6 specimens $/ \mathrm{m}^{2}$ in $\mathrm{KS} 16$ and $\mathrm{KS} 40$, respectively) and the lowest in winter and early spring seasons (239.8 and 312.9 specimens $/ \mathrm{m}^{2}$ in $\mathrm{KS} 16$ and $\mathrm{KS} 40$, respectively). The mean abundance of insect community in KS40 was the highest in spring season $\left(118 \mathrm{specimens} / \mathrm{m}^{2}\right)$ and the lowest in autumn (18 specimens $/ \mathrm{m}^{2}$ ). In KS16, the mean seasonal abundance of insect community was more equal throughout the year, varying from 142 specimens $/ \mathrm{m}^{2}$ in summer to $213 \mathrm{specimens} / \mathrm{m}^{2}$ in winter. Total abundance of fully aquatic taxa community in KS16 ranges from 60 specimens $/ \mathrm{m}^{2}$ in February to 1300 specimens $/ \mathrm{m}^{2}$ in March. Total abundance of fully aquatic taxa in KS40 ranges from 200 specimens $/ \mathrm{m}^{2}$ in March to 1246.4 specimens $/ \mathrm{m}^{2}$ in July. Much higher total abundance of fully aquatic taxa is linked to G. balcanicus mass occurrence, which reaches 1267 specimens $/ \mathrm{m}^{2}$ in July in KS40. G. balcanicus constitutes nearly $65 \%$ of the total collected material. There are no statistically significant differences in diversity index values between the total assemblage of KS16 and the total assemblage of KS40. The comparison of the insect and fully aquatic invertebrate communities of both springs (i.e. 24 samples) has revealed that $\mathrm{S}$ does not differ significantly, $\mathrm{N}$ and $\operatorname{ES}(9)$ are significantly lower among insects than fully aquatic invertebrates, while the ' $\mathrm{J}, \mathrm{d}, \mathrm{H}(\operatorname{loge})$ and 1-Lambda' indices have significantly higher values for insects than for fully aquatic invertebrate communities (Fig. 3).

The SIMPER analysis conducted with the whole assemblage (Appendix 5A1) indicates that G. balcanicus dominates in both springs, but the subdominant taxa of the assemblages are different in the studied assemblages, i.e. Asselus aquaticus, Thremma anomalum in KS16 and Pisidium casertanum, Radix labiata in KS40. Although diversity indices do not reveal significant differences between the assemblages of KS16 and KS40, the NMDS analysis distinctively separates their composition when $G$. balcanicus was included as well as when it was excluded from the analysis (Fig. 4A and C). In the absence of $G$. balcanicus, the dominant taxa in KS40 were
R. labiata, P. casertanum and Glossiphonia nebulosa, while in KS16 A. aquaticus and Thremma anomalum dominated. Our results revealed that the average dissimilarity between KS16 and KS40 when G. balcanicus was excluded was much higher $(93.95 \%)$ than when $G$. balcanicus was included in the analysis $(55.51 \%)$.

As only two to four samples were available from each season for each of the studied springs, it was impossible to obtain significance of diversity indices for differences between the seasons. Nevertheless, the NMDS analysis conducted with the whole assemblages (Fig. 4B) indicates that the most distinctive communities in both springs respectively appear in February. The assemblages from the other months from both springs taken separately are more similar but still remain different in April. The assemblages of both springs from May to October have stable community composition, but from October the communities become more dissimilar again. In terms of within-site similarity, the communities from December to January are very (KS40) dissimilar or remain distinct (KS16) from the summer assemblages.

The SIMPER analysis reveals that winter is the most dissimilar to other seasons (65.15-70.74\%) than spring, whereas, summer and autumn are relatively similar to each other (44.45-52.96\%). Winter assemblages remain also the most diverse (Appendix 5). The characteristic taxa of winter assemblages, in addition to $G$. balcanicus, include A. aquaticus, $P$. casertanum, $R$. labiata, G. nebulosa, Halesus sp. and Micropterna sp. In spring, G. balcanicus, A. aquaticus and Silo pallipes are the most frequently recorded species. On the other hand, G. balcanicus is the only species that significantly contributes to the summer and autumn assemblages of both springs.

The NMDS and SIMPER results reveal a somewhat different seasonal pattern when $G$. balcanicus was excluded from the analyses (Fig. 4D, Appendix 5B2). When KS16 and KS40 are analysed separately, then NMDS separates two groups of spring assemblages (winter-spring and summer-autumn), but the separation is much less pronounced and there are two outliers, KS16.31.05 and KS40.29.06. For example, the KS16 community of December remains more similar to June than to the communities of January and February, respectively, while the KS40 communities from January and February are positioned between the spring and summer communities. The SIMPER analysis conducted without $G$. balcanicus indicates A. aquaticus, $P$. casertanum and R.labiata as characteristic taxa of the winter and spring communities. On the other hand, A. aquaticus, $T$. anomalum and R. labiata mainly contribute to the summer communities, while the leech Glossiphonia balcanica is a characteristic species of the autumn assemblages. The results of SIMPER, when all the taxa were included in the analysis, revealed the highest dissimilarity between winter and summer $(67.2 \%)$ and the lowest between summer and autumn $(36.63 \%)$. On the other hand, when G. balcanicus was excluded from the analysis, the highest dissimilarity was detected between spring and autumn $(87.87 \%)$, while the lowest was found between winter and spring $(80.45 \%)$.

The importance of $G$. balcanicus as the main component of spring communities can be seen from the results of the cluster analysis (Fig. 5). When all taxa were analysed, the spring assemblages similarity (Fig. 5A) revealed a clear phenological pattern. The cluster analysis with cut off at the $40 \%$ level 

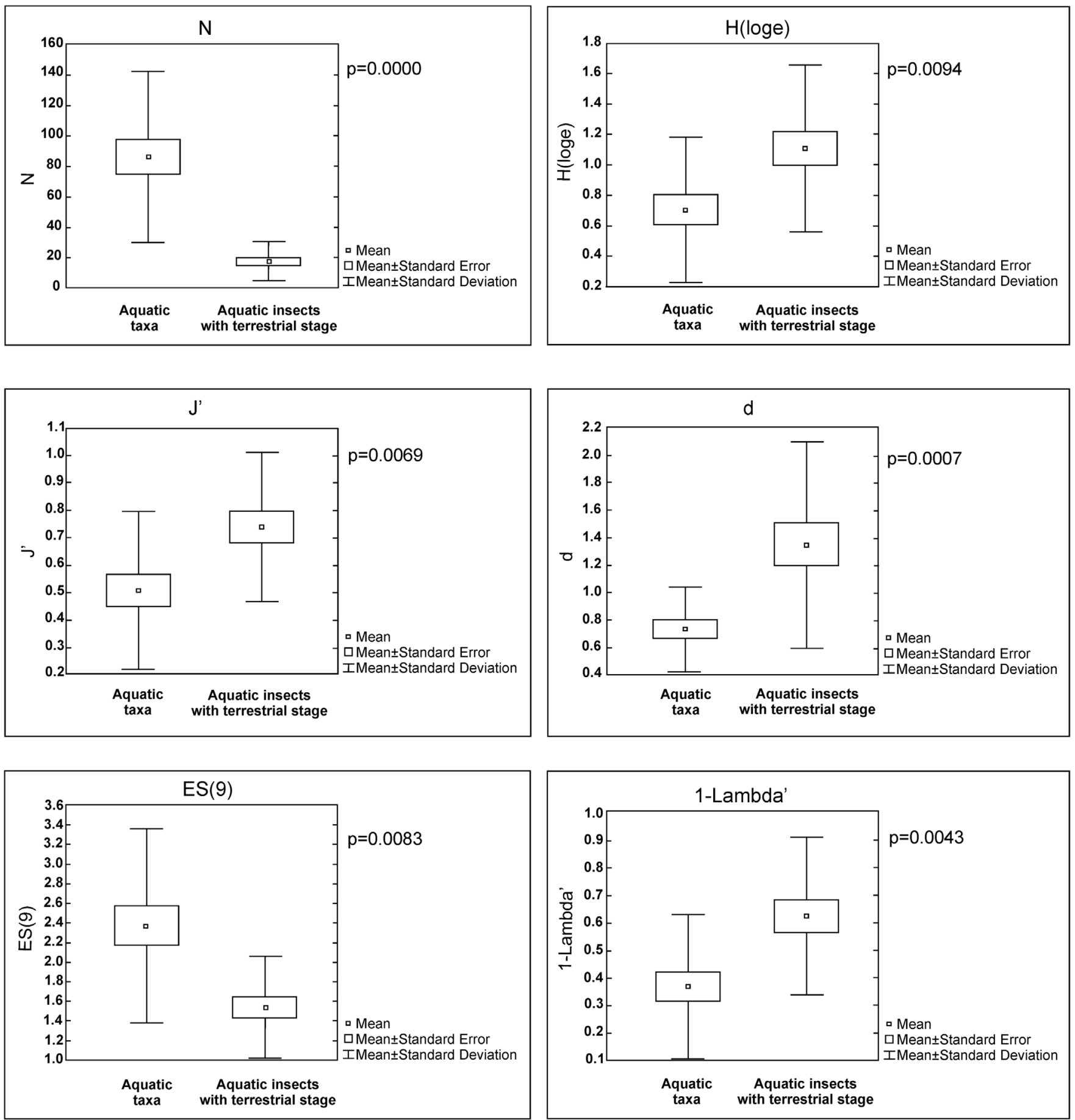

Fig. 3. Diversity indices - statistical parameters (N - abundance, ES(n) - rarefaction, d - Margalef Index, J' - Pielou Index, 1-Lambda' Simpson Index, H(loge) - Shannon Index).

revealed strong dissimilarity of the winter communities of KS16 one another, whereas the winter communities of KS40 were grouped together with the early spring communities. The communities of late spring, summer and autumn of both springs aggregate together and reveal strong similarity to each other. It seems that the switch from the winter-early spring communities to the late spring-summer-autumn ones takes time in November/December and in April/May when the monthly mean air temperature reaches $7.6-10.6{ }^{\circ} \mathrm{C}$. On the other hand, when G. balcanicus was excluded from the analysis, there was no clear pattern that could be related to the seasonal changes (Fig. 5B). The winter assemblages of KS16 reveal strong dissimilarity to each other, while the winter assemblages of KS40 are grouped together with the early spring assemblages. The communities of the late spring, summer and autumn assemblages do not reveal any trends, and 

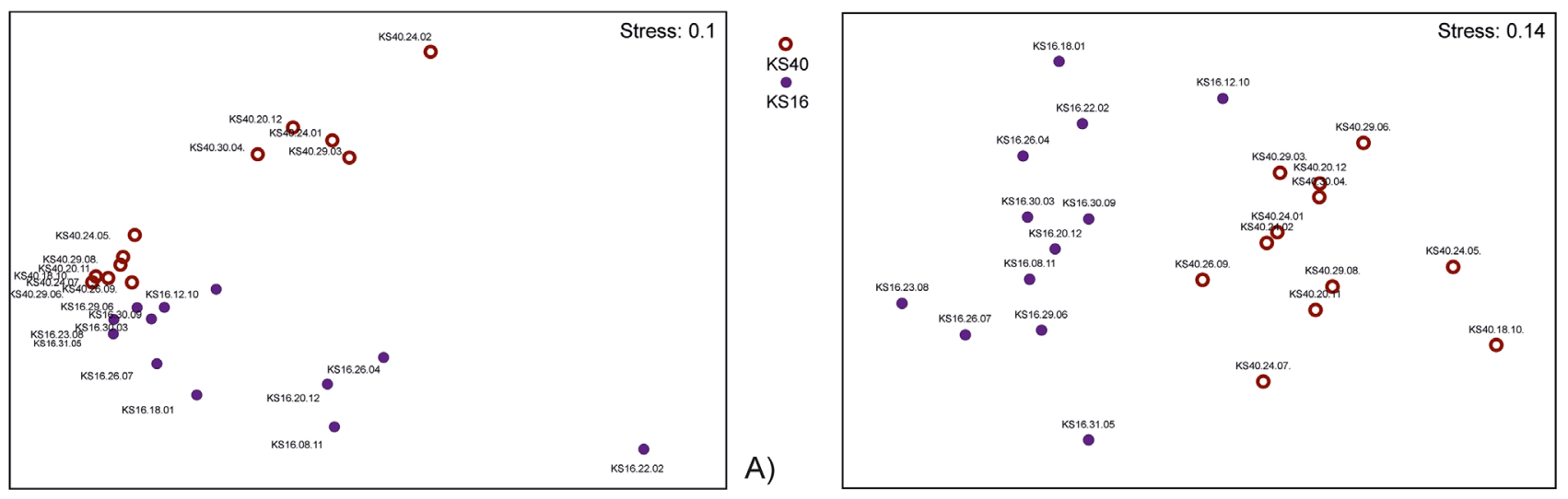

C)
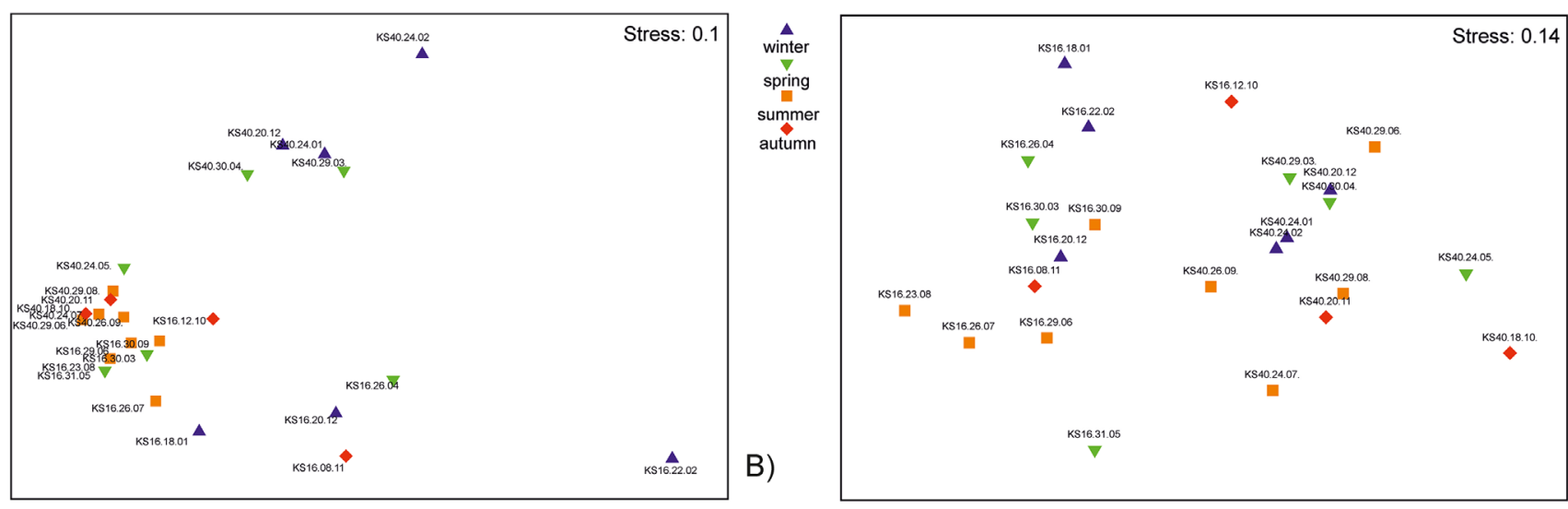

D)

Fig. 4. Results of Non-metric MultiDimensional Scaling of macroinvertebrate communities in springs KS16 and KS40 throughout the seasons. A and B - with all taxa included, C and D - with G. balcanicus excluded from the analysis.

samples from different months reveal strong dissimilarity. Moreover, when G. balcanicus was excluded, we did not find any correlations between the communities and the mean monthly air temperature.

\section{Discussion}

Springs are important to maintain aquatic invertebrate diversity, especially in regions where other water habitats, such as large lakes and rivers, are limited (Davis et al., 2017). In this study, 51 taxa were recorded from two springs located in the mountainous region of western Kosovo. Regarding taxonomic richness, the assemblages of both springs were dominated by insects. The highest species richness was recorded among the Trichoptera, which is consistent with many studies (e.g. Savić et al., 2017). This study proves that the investigated assemblages of insects had significantly higher species richness and evenness than communities of other invertebrates (Fig. 3). However, the overall abundance of fully aquatic taxa was much higher, but evenness was much lower in relation to insects other than beetles. This is mostly linked to the dominance of $G$. balcanicus, a widespread and abundant species in small rheocrenes in the Balkans (Mamos et al., 2014). Similarly, in Iberian springs, Echinogammarus reaches density of an order of magnitude higher than the other taxa (Barquín and Death, 2004).
Our results demonstrate that monthly sampling of Prokletije springs across all seasons yields greater aquatic macroinvertebrate diversity than single annual or seasonal sampling. Some studies (e.g. Sandlund and Aagaard, 2004) indicate that even when we combine different sampling methods and make a reasonable sampling effort in collecting specimens, as many as $50 \%$ of species will be missed by single annual sampling. However, undertaking surveys monthly or at least seasonally raises a number of practical considerations in relation to sampling techniques and the impact on the crenic assemblage. First of all, there is no clear and standardised protocol for sampling aquatic macroinvertebrate communities in springs and different methods are used in various studies. Rosati et al. (2016) summarise the literature on semiquantitative sampling methods in springs taking into account their potential impacts on spring habitats and biota. They show that a multihabitat proportional approach is the most suitable for biodiversity inventories. Many authors (e.g. Gooch and Glazier, 1991; Gerecke et al., 2007) have noted that because springs are fragile ecosystems, the sampling survey which implied more frequent sampling (and also samplings in all microhabitats) could be destructive to the environment and the biota.

Yet, detailed studies on the impact of multiple sampling in springs and the recovery time of a community from a disturbance such as digging and diminishing of different 

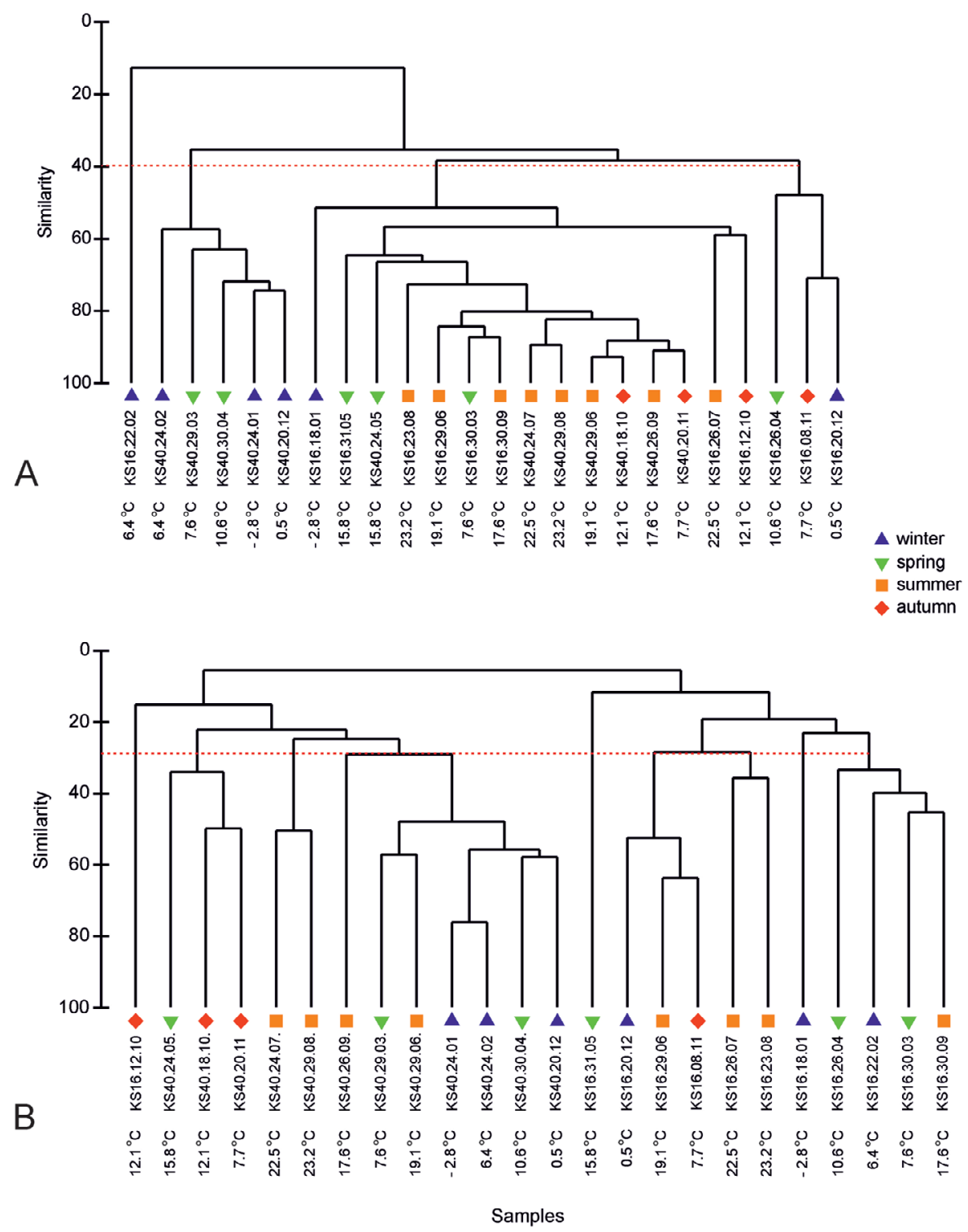

Fig. 5. Cluster analysis presenting similarity among samples compared to mean month air temperatures when A - all taxa are included, B - G. balcanicus is excluded.

microhabitats and substrata are largely unknown. In addition to the extent of the disturbance event, colonisation by the dispersive adult stage or migration upwards via the spring brook into the spring play an important role in the recovery of crenic communities. von Fumetti et al. (2017) have studied 35 rheocrene springs along the river Cvrcka in the Dinaric Karst and found that dispersal and colonisation mainly take place via the watercourse corridor by adult insect stages. The proportion of taxa with flying, dispersive adult stages was high (two thirds) in the springs of the above-mentioned study and is comparable with the results of our study.

Moreover, it should not be forgotten that the financial costs and time required to collect, process and identify samples can constitute adverse factors for multiple sampling in springs. This can be especially true for small rheocrenic springs. As a consequence, sampling of springs has typically been undertaken in the form of single sampling per year. This raises the question: What is the optimum time to collect samples for biodiversity assessment?

The results of our study indicate that winter assemblages of fully aquatic invertebrates in Prokletije springs remain the most diverse. Almost all mean diversity indices have revealed that the community of fully aquatic taxa of the studied springs exhibits the highest values in winter. On the other hand, the winter communities of insects (without beetles) have revealed the highest rarefaction and values of Shannon Index, while the other diversity indices, such as the Margalef and Simpson indices, showed similar values for winter, spring and summer communities, even higher in summer (Appendix 4). Nearly all diversity indices are significantly higher for insects than for solely aquatic invertebrates. These results would imply that sampling time can affect diversity indexing of spring 
assemblages and that the difference between fully aquatic invertebrates and insects that inhabit springs should be taken into consideration.

According to diversity indices, the most different assemblages in both studied springs appear in February. This was confirmed by the results of SIMPER analysis, which revealed that when the whole assemblages were analysed, winter was the most dissimilar to other seasons. However, it is worth noting that this pattern was not present in spring KS16 when G. balcanicus, a dominant species in the assemblages of both springs, was excluded from the analysis. Our study revealed that most taxa-rich assemblages were found in summer. Moreover, the highest number of exclusive species collected only in one season in both springs was found in summer and autumn (Appendices 2 and 3). Therefore, if we would like to draw conclusions from the study, then we would say that if we had to choose one season for sampling Prokletije Mountian springs, sampling in summer would probably provide the most taxa-rich assemblages, but with lower values of diversity indices of fully aquatic invertebrates, and partly of insects communities, (Appendix 4) in comparison to other respective seasons. However, if we would like to complete the dataset with the most distinctive assemblage as possible, then sampling in February can be recommended for the investigated springs.

All this means that the timing of the survey(s) depends on the scientific aims and information required for the ongoing management activities as well the ecology of specific taxa that allows for the use of certain methods for their collecting. Namely, it is well known that the usage of some methods for spring biodiversity inventories, such as sweep nets or emergence traps, is possible in the specific period of the year, usually in summer and autumn. For example, univoltine aquatic insect orders such as Ephemeroptera, Plecoptera and Trichopteran families Limnephilidae and Leptoceridae typically emerge as adults during summer and autumn (Wallace et al., 2003).

It raises the question to what extent the investigated communities were dependent on weather conditions. The results show that when $G$. balcanicus was included in the analyses, the monthly mean air temperature explained well the observed pattern in the communities similarity. On the other hand, when the main dominant taxa - G. balcanicus was excluded, no clear seasonal pattern was found (Fig. 5). This can indicate that the seasonal pattern observed in the studied communities may reflect mainly seasonal changes in the abundance of $G$. balcanicus related to temperature, while the appearance of the other taxa does not follow the seasonality or is affected by other factors.

Unfortunately, results were obtained from only two springs. The sampling in difficult mountain conditions was time consuming and did not allow for gathering material from more springs in the region with monthly resolution. Due to this fact, the presented observations have a limited explanatory value, especially when taking into account the distinct differences in assemblages composition. Nevertheless, KS16 and KS40 rheocrenes were chosen for testing the abovementioned hypotheses among $\sim 50$ other springs preliminarily investigated as good examples of standard character of springs in the region. As the studied springs are typical for the Prokletije Mountains, the concluding remarks may be extrapolated to all Western Balkan springs. A new, supplementary survey of aquatic insects diversity currently conducted in more than 50 springs in the region should complete the verification of the hypotheses postulated here. Nonetheless, it cannot include monthly sampling of the studied sites, which is an undoubted advantage of the presented research.

\section{Supplementary Material}

Supplementary material provide by the authors.

The Supplementary Material is available at https:/www.kmaejournal.org/10.1051/kmae/2018043/olm.

Acknowledgements. The authors are grateful to Peter Glöer (Germany), Clemens Grosser (Germany), Bogić Gligorović (Montenegro), Halil Ibrahimi (Kosovo) and Tibor Kovacs (Hungary) for help in the identification of the material used in this study. Moreover, we are thankful to Agnieszka Mroczkowska for her valuable assistance in the laboratory analysis of the Chironomidae samples, Tomasz Mamos for preparing the map of the study area and professional English translator Marta Koniarek for linguistic corrections.

\section{References}

Barquín J, Death RG. 2004. Patterns of invertebrate diversity in streams and freshwater springs in Northern Spain. Arch Hydrobiol 161: 329-349.

Botosaneanu L. 1998. Studies in Crenobiology. The Biology of Springs and Springbrooks. Leiden: Backhuys Publishers, $261 \mathrm{pp}$.

Bottazzi E, Bruno MC, Pieri V, Di Sabatino A, Silveri L, Carolli M, Rossetti G. 2011. Spatial and seasonal distribution of invertebrates in Northern Apennine rheocrene springs. J Limnol 70: 77-92.

Clarke KR, Gorley RN. 2001. PRIMER v5: User Manual/Tutorial. Plymouth: PRIMER-E, p. 91.

Davis J, Kerezsy A, Nicol SC. 2017. Springs: conserving perennial water is critical in arid landscapes. Biol Conserv 211: 30-35.

Dmitrović D, Savić D, Pešić V. 2016. Discharge, substrate type and temperature as factors affecting gastropod assemblages in springs in northwestern Bosnia and Herzegovina. Arch Biol Sci 68: 613-621.

European Commission (EC). 2003. Common Implementation Strategy for the Water Framework Directive (2000/60/EC), Guidance Document No. 11: Planning Processes. Luxembourg: Office for Official Publications of the European Communities.

Gerecke R, Maiolini B, Cantonati M. 2007. Collecting meio- and macrozoobenthos in springs. In: Cantonati M, Bertuzzi E, Spitale D, eds. The Spring Habitat: Biota and Sampling Methods. Trento: Museo Tridentino di Scienze Naturali, pp. 265-274.

Gerecke R, Cantonati M, Spitale D, Stur E, Wiedenbrug S. 2011. The challenges of long-term ecological research in springs in the northern and southern Alps: indicator groups, habitat diversity, and medium-term change. J Limnol 70: 168-187.

Gooch JL, Glazier DS. 1991. Temporal and spatial patterns in midAppalachian springs. Mem Entomol Soc Can 155: 29-49.

Kubíková L, Simon OP, Tichá K, Douda K, Maciak M, Bílý M. 2012. The influence of mesoscale habitat conditions on the macroinvertebrate composition of springs in a geologically homogeneous area. Freshw Sci 31: 668-679.

Mamos T, Wattier R, Majda A, Sket B, Grabowski M. 2014. Morphological vs. molecular delineation of taxa across montane 
regions in Europe: the case study of Gammarus balcanicus Schäferna, (Crustacea: Amphipoda). J Zool Syst Evol Res 52: 237-248.

Pešić V, Dmitrović D, Savić A, von Fumetti S. 2016. Studies on eucrenal-hypocrenal zonation of springs along the river mainstream: a case study of a karst canyon in Bosnia and Herzegovina. Biologia 71: 809-817.

Pešić V, Dmitrović D, Savić A, Milošević Dj, Zawal A, VukašinovićPešić V, von Fumetti S. in press. Application of macroinvertebrate multimetrics as a measure of the impact of anthropogenic modification of spring habitats. Aquat. Conserv Mar Freshw Ecosyst. DOI:10.1002/aqc.3021

Płóciennik M, Dmitrović D, Pešić V, Gadawski P. 2016. Ecological patterns of Chironomidae assemblages in Dynaric karst springs. Knowl Manag Aquat Ecosyst 11: 1-19.

Rosati M, Cantonati M, Fenoglio S, Segadelli S, Levati G, Rossetti G. 2016. Is there an ideal protocol for sampling macroinvertebrates in springs? J Freshwater Ecol 32: 199-209.

Sandlund OT, Aagaard K. 2004. Long-term monitoring and research in an alpine-boreal watershed: Atndalen in perspective. In: Sandlund OT, Aagaard K, eds. The Atna River: Studies in an
Alpine-Boreal Watershed, Developments in Hydrobiology, Vol. 177. Dordrecht: Springer, pp. 203-208.

Savić A, Dmitrović D, Pešić V. 2017. Ephemeroptera, Plecoptera and Trichoptera assemblages of karst springs in relation to environmental factors: a case study in central Bosnia and Hercegovina. Turk J Zool 41: 119-129.

Springer AE, Stevens LE. 2008. The sphere of discharge of springs. Hydrogeol J 17: 83-93.

StatSoft Inc. 2015. STATISTICA (data analysis software system), version 12. Available from www.statsoft.com.

Von Fumetti S, Dmitrović D, Pešić V. 2017. The influence of flooding and river connectivity on macroinvertebrate assemblages in rheocrene springs along a third-order river. Fund Appl Limnol 190: 251-263.

Von Fumetti S, Nagel P, Scheifhacken N, Baltes B. 2006. Factors governing macrozoobenthic assemblages in perennial springs in north-western Switzerland. Hydrobiologia 568: 467-475.

Wallace ID, Wallace B, Philipson GN. 2003. Case-bearing caddis larvae of Britain and Ireland. Cumbria, UK: Freshwater Biological Association Scientific Publication No. 61, p. 259.

Cite this article as: Berlajolli V, Płóciennik M, Antczak-Orlewska O, Pešić V. 2019. The optimal time for sampling macroinvertebrates and its implications for diversity indexing in rheocrenes - case study from the Prokletije Mountains. Knowl. Manag. Aquat. Ecosyst., $420,6$. 